\title{
A Expansão da EAD à Luz dos Decretos Governamentais e o Novo Marco Regulatório da EaD
}

\author{
RICARDO, Jaison Sfogia ${ }^{[1]}$
}

RICARDO, Jaison Sfogia. A Expansão da EAD à Luz dos Decretos Governamentais e o Novo Marco Regulatório da EaD Revista Científica Multidisciplinar Núcleo do Conhecimento. Edição 06. Ano 02, Vol. 01. pp 292-300, Setembro de 2017. ISSN:2448-0959

O presente artigo apresenta o crescimento da oferta de cursos na modalidade a distância no Ensino Superior. Para tanto, aponta o quadro histórico que permite explicar esse crescimento e detecta a preocupação do Estado com o oferecimento de cursos em EaD. Recolhe os principais decretos que a organizam. Por fim, apresentam-se as mudanças que o último decreto presidencial e a sua respectiva portaria normativa estabelecem para a expansão da $\mathrm{EaD}$, particularmente, das Instituições de Ensino Superior privadas.

Palavras-chave: Ensino a Distância. Decretos. Instituições de Ensino Superior.

\section{INTRODUÇÃO}

A Educação a Distância (EaD), no Brasil, é um fenômeno educacional que se inicia no fim do século passado e expande-se de forma exponencial no decorrer desses últimos 20 anos no ambiente do Ensino Superior.

As políticas públicas de expansão da $\mathrm{EaD}$ estão ligadas aos critérios fixados no decorrer de sua implementação: credenciamento, recredenciamento, supervisão e avaliação das suas instituições e cursos. Para tanto, apresenta um quadro histórico de decretos presidenciais que garantiram a construção dessa modalidade de ensino no Brasil e os recentes documentos oficiais de 2017: Portaria Normativa $\mathrm{n}^{\circ} 11$, de 20 de junho de 2017, que regulamenta o Decreto ${ }^{\circ}$ 9.057, de 25 de maio de 2017.

Outro aspecto, por fim, que perpassa o artigo, é o papel destacado da participação das Instituições de Ensino Superior (IES) privadas no processo de crescimento da $\mathrm{EaD}$ e suas reivindicações na participação decisória das políticas públicas voltadas para esse Ensino. 


\section{BREVE HISTÓRICO DA EAD NO BRASIL}

Do ponto de vista histórico, é de consenso geral que a Educação a Distância é uma modalidade de ensino muito antiga no mundo ocidental. Hoje é definida como um "aprendizado planejado que ocorre normalmente em um lugar diferente do local de ensino, exigindo técnicas especiais de criação do curso e de instrução, comunicação por meio de várias tecnologias e disposições organizacionais e administrativas especiais". (MOORE; KEARSLEY, 2008, p. 2)

Como o objetivo da presente reflexão é analisar a expansão da EaD no Ensino Superior, estabelece-se como fato histórico propulsor a Lei $\mathrm{n}^{\circ}$ 9.394, de 20 de dezembro de 1996, Lei das Diretrizes e Base de Educação Nacional (LDB), considerada o leitmotiv dessa expansão, na medida em que o Estado reconhece, legitima e assegura a viabilidade do Ensino a Distância, conforme estabelece o artigo 80.

A aprovação da Lei de Diretrizes e Bases da Educação Nacional abriu inúmeras possibilidades para a expansão da modalidade da Educação a Distância, visto que flexibilizou os procedimentos a serem adotados na criação e implementação desses cursos no Brasil.

O grande salto é percebido claramente, em meados dos anos 2000, com a massificação das Tecnologias de Informação e Comunicação (TICs), o apoio de ferramentas tecnológicas do computador e a modelagem de Ambientes Virtuais de Aprendizagem (AVA).

Segundo dados do Censo da Educação Superior de 2016, "a participação da Educação a Distância em 2006 era de 4,2\% do total de matrículas em cursos de graduação e aumentou sua participação em 2016 para 18,6\%". (BRASIL, 2017a, p. 7)

Vê-se, diante disso, que a expansão da EaD é uma realidade, conferindo-lhe importância no quadro educacional brasileiro.

\section{DECRETOS QUE PROMOVERAM A EXPANSÃO DA EAD NO ENSINO SUPERIOR}

Apresentado um breve histórico da $\mathrm{EaD}$, a análise avança para a compreensão dos documentos que a reconheceram legalmente e, portanto, a regulamentaram, a partir da promulgação da Lei nº 9.394/1996.

\subsection{Decreto $\mathrm{n}^{0}$ 5.622, de 19 de dezembro de 2005, regulamentava o artigo 80 da LDB}

Considerado à época o marco regulatório da Educação a Distância, o Decreto $n^{\circ}$ 5.622/2005 buscava não apenas regulamentar artigo 80 da Lei de Diretrizes e Bases da Educação Nacional (Lei n 9.394/1996), mas também funcionar como política pública indutora com vistas à ampliação e ao fortalecimento da $\mathrm{EaD}$ no Brasil. Essa Lei estabelecia normas e tratava, principalmente, sobre as regras de credenciamento, recredenciamento, supervisão e critérios de avaliação das instituições e cursos.

Por fim, determinava a obrigatoriedade da participação presencial dos estudantes diante de atividades escolares definidas: avaliação, estágio, defesa de Trabalho de Conclusão de Curso (TCC) e uso de laboratórios. 
O Decreto $\mathrm{n}^{\circ}$ 5.773/2006 dispõe sobre o exercício das funções de regulação, supervisão e avaliação de Instituições de Ensino Superior e cursos superiores de graduação e sequenciais no sistema federal de ensino. Nesse Decreto, destaca-se a divisão de tarefas dos órgãos públicos educacionais para o credenciamento, funcionamento, supervisão e avaliação, como estabelecidos em seu artigo $3^{\circ}$.

O Decreto $n^{\circ}$ 5.773/2006 alterou profundamente o papel exercido pela Secretaria de Educação a Distância (SEED). Desse modo, tornaram-se mais claras as relações estabelecidas entre as instituições de ensino e o MEC.

Nesse passo, no Capítulo II do Decreto $n^{\circ} 5.773 / 2006$ foi disposta a Subseção V para tratar do credenciamento específico para oferta de Educação a Distância.

\subsection{Decreto $\mathrm{n}^{0}$ 6.303, de 12 de dezembro de 2007, altera o Decreto $\mathrm{n}^{\circ}$ 5.622, de 19 de dezembro de 2005}

O Decreto $n^{\circ}$ 6.303/2007 foi editado para adequações nos Decretos $n^{\circ}$ 5.622/2005 e 5.773/2006. Estabelece normas detalhadas para o credenciamento, renovação, supervisão das Instituições de Ensino a Distância e descentraliza o papel da União, ao permitir que os Sistemas de Ensino possam participar desses processos.

Além de ratificar a obrigatoriedade de que as atividades presenciais deverão ser realizadas nas sedes das Instituições ou em seus polos.

Devido ao alto nível de exigência para o credenciamento, recredenciamento, supervisão e avaliação, esse Decreto provocou grandes críticas das IES particulares.

\section{AS ÚLTIMAS ATUALIZAÇÕES OFICIAS}

Como foram avaliados, anteriormente, os sucessivos decretos ligados à Educação a Distância permitiram por um lado incorporar a EaD à política de Estado que visou à expansão e, por outro, estabelecer critérios de qualidade para essa modalidade de ensino por meio de regras para credenciamento, supervisão e avaliação.

Nesse passo, conhecido como o novo marco regulatório para a Educação a Distância no Brasil, o Ministério da Educação editou a Portaria Normativa n ${ }^{\circ}$ 11, de 20 de junho de 2017, que regulamenta o Decreto $\mathrm{n}^{\mathrm{o}}$ 9.057, de 25 de maio de 2017, com o objetivo de ampliar a oferta de cursos superiores na modalidade a distância e melhorar a qualidade da atuação regulatória do Ministério da Educação (MEC).

Entre as novidades, a nova regulamentação permite que as Instituições de Ensino Superior se credenciem para oferta de cursos de $\mathrm{EaD}$, na graduação e na pós-graduação lato sensu, sem a necessidade de credenciamento para modalidade presencial. (SANTOS JÚNIOR, 2017)

Com isso, a nova regra abre a oportunidade para o credenciamento exclusivo de EaD e desmistifica a questão da modalidade de ensino.

Cumpre ainda averiguar a regra estabelecida no parágrafo terceiro do artigo $1^{\circ}$ da Portaria Normativa $n^{\circ}$ 11, que mantém a exigência da oferta regular de curso de graduação, independente da modalidade, como 
condição indispensável para manutenção do credenciamento das IES. (BRASIL, 2017b)

Outra flexibilização surgiu nos procedimentos de avaliação in loco, que ocorrerão apenas nas sedes das IES, sem a necessidade de verificação dos polos.

Nesse contexto, a avaliação in loco no endereço sede da IES visará à verificação da existência e adequação de metodologias, infraestrutura física, tecnológica e de pessoal que possibilitem a realização das atividades previstas no Plano de Desenvolvimento Institucional (PDI) e no Projeto Pedagógico do Curso (PPC). (BRASIL, 2017b)

Outra inovação que a Portaria traz é a criação de polos de Educação a Distância pelas próprias IES já credenciadas para esta modalidade de ensino. Essa Portaria detalha a quantidade de polos que as IES poderão criar, baseado no Conceito Institucional (CI) mais recente da Instituição.

Como se vê, o CI varia de 1 a 5 e, com as novas definições, Instituições de Ensino Superior que possuírem CI 3 poderão criar até 50 polos por ano, enquanto as com CI 4 poderão criar 150 e as com CI 5 poderão abrir até 250 novos polos $\mathrm{EaD}$ anualmente.

Expostas as principais mudanças implementadas pela Portaria e com o intuito de nortear o foco do artigo, depreende-se que essas alterações estão fortemente alicerçadas em instituições privadas com vistas à ampliação e ao fortalecimento da EaD no país.

Embora haja um discurso oficial de se cumprir a meta 12 do Plano Nacional de Educação, "elevar a taxa bruta de matrícula na Educação Superior para 50\% e a taxa líquida para 33\% da população de 18 a 24 anos, assegurada a qualidade da oferta e expansão para, pelo menos, $40 \%$ das novas matrículas, no segmento público", tanto o decreto presidencial como a Portaria Normativa estabelecem critérios mais flexíveis para o Ensino a Distância, considerando um novo marco regulatório da $\mathrm{EaD}$ no Brasil. (BRASIL, 2014, p. 41)

Observa-se, assim, que o nível de exigência para o funcionamento da $\mathrm{EaD}$, por meio dos decretos, representou uma disputa político-ideológica entre Associação Brasileira de Mantenedoras de Ensino Superior (ABMES) e o MEC, por aquela possuir a hegemonia das matrículas e cursos ofertados.

Nessa junção, segundo o Sindicato das Mantenedoras de Ensino Superior, as matrículas nos cursos de nível superior a distância registraram, de 2009 a 2015, um crescimento de 66\%: um aumento de $90 \%$ na rede privada e uma queda de $26 \%$ na rede pública. (SEMESP, 2017)

Em relação ao período de 2014 a 2015, o crescimento na rede privada chegou a 5,2\% (1,20 milhão de matrículas para 1,26 milhão) e, em contrapartida, na rede pública ocorreu uma queda de 7,9\% nas matrículas (eram 139 mil em 2014 e reduziram para 128 mil em 2015). (SEMESP, 2017)

Pode-se ainda fazer uma comparação com os dados que compõem o levantamento do Censo da Educação Superior de 2016, realizado anualmente pelo Instituto Nacional de Estudos e Pesquisas Educacionais Anísio Teixeira (Inep), que foram apresentados pelo Ministério da Educação em agosto de 2017, que apontam um crescimento da oferta da Educação a Distância.

De acordo com o levantamento, em 2016 quase três milhões de alunos ingressaram em cursos de educação superior de graduação. Desse total, $82,3 \%$ em instituições privadas. Após uma queda observada 
em 2015, o número de ingressantes cresceu 2,2\% em 2016. Isso ocorreu porque a modalidade a distância aumentou mais de $20 \%$ entre os dois anos, ao passo que nos cursos presenciais houve um decréscimo de 3,7\% no número de ingressantes. (BRASIL, 2017a)

Com isso, pode-se afirmar que essas alterações corroboram para a expansão ainda maior da modalidade EaD; quanto à qualidade, a médio e longo prazo, as avaliações dirão.

\section{CONCLUSÃO}

A partir do exposto, pode-se concluir que a modalidade de EaD no Ensino Superior no Brasil teve seu grande impulso nesses últimos 20 anos graças às políticas de garantias de funcionamento e sistemas de avaliação permanentes.

Também, é possível considerar que a sua expansão associa-se às Instituições privadas e que estas são, atualmente, hegemônicas diante das públicas e por isso exigiram, durante esse processo, políticas públicas que facilitassem o seu crescimento.

Nesse contexto, o Decreto $\mathrm{n}^{\circ}$ 9.057/2017 e a Portaria Normativa $\mathrm{n}^{\circ} 11$, de 20 de junho de 2017 cedem às pressões e contemplam os interesses das IES privadas, favorecendo o credenciamento e recredenciamento de novos cursos a distância e simplificando a supervisão e avaliação.

\section{REFERÊNCIAS}

BRASIL. Ministério da Educação. Censo da Educação Superior 2016: Notas Estatísticas. Brasília, 2017a. Disponível em: <http://portal.mec.gov.br/index.php?option=com_docman $\&$ view=download \&alias=71221-notas-sobre-censo-educacao-superior-2016-pdf\&category_ slug=agosto-2017-pdf\&Itemid=30192> Acesso em: 10 set. 2017.

BRASIL. Ministério da Educação. Portaria Normativa n ${ }^{\circ}$ 11, de 20 de junho de 2017b. Estabelece normas para o credenciamento de instituições e a oferta de cursos superiores a distância, em conformidade com o Decreto ${ }^{\circ}$ 9.057, de 25 de maio de 2017. Diário Oficial da República Federativa do Brasil, Brasília, DF, 21 jun. 2017.

BRASIL. Ministério da Educação. Planejando a Próxima Década: Conhecendo as 20 Metas do Plano Nacional de Educação. Brasília, 2014. Disponível em: <http://pne .mec.gov.br/images/pdf/pne_ conhecendo_20_metas.pdf>Acesso em: 1 set. 2017.

MOORE, M. G.; KEARSLEY, G. Educação a Distância: uma visão integrada. São Paulo: Thompson, 2008.

SANTOS JÚNIOR, J. dos. Novo Marco Regulatório da Educação a Distância: O início da quebra de paradigmas da EAD no Brasil. São Paulo, 2017. Disponível em: http://abed.org.br/arquivos/Publicado_Novo_Marco_Regulatorio_EAD_Jair_Santos_Jr.pdf Acesso em: 1 set. 2017.

SEMESP. SINDICATO DAS MANTENEDORAS DE ENSINO SUPERIOR. Mapa do Ensino Superior 
no Brasil 2017. São Paulo, 2017. Disponível em: <http://www.semesp.org.br/site/pesquisas/mapa-doensino-superior-2017/> Acesso em: 9 set. 2017.

11 Pós-graduando em Tecnologias de Informática na Educação pela Universidade Estadual de Londrina (UEL). Pós-Graduado em Direito Constitucional. Graduado em Direito e em Administração Legislativa. Membro do International Council for Open and Distance Education (ICDE) e membro associado da Associação Brasileira de Educação a Distância.

\section{PUBLIQUE SEU ARTIGO CIENTÍFICO EM:}

https://www.nucleodoconhecimento.com.br/enviar-artigo-cientifico-para-submissao 